\title{
The Relationship Between Family Cohesion and Self- efficacy of Different Grades College Students in Mainland China
}

\author{
Jiyu Wen ${ }^{1, \dagger}$, Shiyun Yang ${ }^{2, \dagger}$, Yihang Yang ${ }^{3, *, \dagger}$ \\ ${ }^{1}$ Dalian University of Foreign Languages, Dalian, Liaoning, 116044, China \\ ${ }^{2}$ Ningbo Foreign Language School, Ningbo, Zhejiang, 315121, China \\ ${ }^{3}$ Duke Kunshan University, Suzhou, Jiangsu, 215316, China \\ *Corresponding author Email: yihang.yang@dukekunshan.edu.cn \\ Those authors contributed equally.
}

\begin{abstract}
The present study examines the relationship between family cohesion and self-efficacy of college students of different grades in mainland China. The research sample is a random selection of college students from mainland China, with 60 students in each of the four grades, for about 240 students. We expected to find that family cohesion is positively correlated with self-efficacy, and the correlation between freshman and senior students is higher than that of sophomores and juniors. We will use the revised General Self-Efficacy Scale (GSE) to assess self-efficacy and Family Adaptability and Cohesion Evaluation Scale (FACES II) to measure family cohesion. We will conduct Pearson product-moment correlation and regression analysis to test our hypotheses.
\end{abstract}

Keywords: Chinese college students, family cohesion, self-efficacy.

\section{INTRODUCTION}

Since the 1980s, many empirical studies have enriched and further developed and supported the selfefficacy theory [1]. These studies showed that selfefficacy affected motivation and behavior and positively impacted individuals' physical and mental health, academic performance, and self-worth [2]. Meanwhile, the family background also had a significant effect on an individual's self-awareness and cognitive development. Because the family is the most basic unit of human life, it is an important place to affect the growth and development of children. Especially in adolescence, the influence of family background on students' self-awareness and academic development was more profound than in the school environment [3]. Thus, family cohesion, adaptability, and self-efficacy significantly impact students' cognition and behavior. Therefore, the present study aimed at exploring the relationship between family cohesion, adaptability, and students' self-efficacy.

Self-efficacy was defined as people's beliefs about their capabilities to produce designated levels of performance that exercised influence over events that affected their lives. Self-efficacy beliefs determine how people feel, think, are self-motivated, and behave [1]. Self-efficacy determines people's feelings, thinking, motivation and behavior. Family cohesion was defined as the emotional bonding that existed between family members. In contrast, adaptability was the family's ability to change its power structure, role relationships, and rules to respond to situational or developmental needs [4]. Family cohesion also refers to the affection, support, helpfulness, and caring among family members [5].

Previous studies on self-efficacy and family cohesion were divided into two main categories. The first category was the relationship between family cohesion and academic burnout. Amani et al. [6] supposed that the majority of the students regarded their families to be coherent, and one of the factors involved in their academic success was family cohesion. Selfefficacy also affects students' academic performance. According to Ahmad et al. [7], students with higher selfefficacy obtained higher scores on 50 mathematical problems tests and planned to study complex subjects. The second category was the effect of family cohesion on children's sense of self-efficacy in treating diseases. 
Nabunya et al. [8] found the need to strengthen family cohesion and communication within families if people enhance adherence self-efficacy among adolescents living with HIV.

Yi et al. have studied the influence between family closeness, adaptability, and self-efficacy of college students, among Chinese students [9]. Their study concluded a positive correlation between home environment and self-efficacy, and home environment could predict self-efficacy. However, their definition of family environment was not clear enough. In another study, the family environment was measured by the dimensions of cohesion, hierarchy, support, and conflict [10]. Thus, our study focused on family cohesion and adaptability. Furthermore, we wanted to classify our experimental subjects into different grades: freshman, sophomore, junior, and senior. Because they were faced with different environments to adapt to university, this paper tried to explore the impact of family cohesion on college students of different grades.

In China, the university was the turning point for most students to develop and move geographically. Asian students, especially Chinese students, had limited educational resources, but parents' high educational value, parental participation, and recognition were significantly negatively correlated with classmates' academic risk [11]. Therefore, family cohesion and adaptability undoubtedly greatly influenced college students who had not yet entered society. Good family cohesion and adaptability could help college students have an optimistic psychological state. Research showed that a more cohesive family could help male college students alleviated the relationship between irritability and obsessive-compulsive disorder (OCD). In contrast, for female college students, family cohesion (flexible family coping strategies and communication atmosphere) could help them alleviate the relationship between suppressed anger and OCD symptoms [12]. In addition, high-level family cohesion may promote subjective well-being through high-level self-concept clarity and hope [13].

The present research aimed to provide spiritual support for college students by establishing good family cohesion and adaptability, developing their interpersonal communication, social education, and selfreflection ability, and helped them produce better selfefficacy. For solutions, good family cohesion requires the joint efforts of parents and children. Family members should have more contact. Research showed that exposure to nature restored individual attributes and contributed to greater dyadic cohesion, and contact with nature effectively improves family cohesion and adaptability [14].

Particularly, college students face pressure from potential and existing peers and integrate into society. College life is transitional, especially for first-year students. It is particularly easy to bear pressure. As firstyear students, they needed to adjust to living away from home for the first time, maintained high levels of academic achievement, and adapted to new social living environments. If not dealt with effectively, these stresses could lead to loneliness and excessive worry [15].

Meanwhile, it was not difficult to find that selfefficacy is crucial to students' academic success. There was strong evidence for the role of self-efficacy and optimism in college students' performance and life adjustment [16]. Self-efficacy, as the confidence or belief of individual success, affected the mentality of college students. There was a study that has shown that stress is negatively correlated to self-efficacy [17]. In other words, if college students had too much pressure, it would not be conducive to the cultivation of selfefficacy and the realization of academic success.

As mentioned before, college students experienced leaving home to study in a new social environment, and family relationships were their single most stable inherent ties. It has not hard to see those parents also played an important role in late adolescence, and positive family relationships could even reduce depression-related symptoms in college students [18]. Therefore, we considered whether family cohesion would serve as a kind of association that college students already had, could affect students' self-efficacy to some extent, and thus achieved academic success.

A good family cohesion and adaptability environment positively influences students' development, including their grades, adaptability to a new environment, and work under pressure. Meanwhile, a relatively strong correlation between family cohesion, family adaptability, and students' self-efficacy may remind parents to care more about their children and strengthen family relationships. There is a clear direction for college educators to guide them on educating college students to be more confident and determined by improving family cohesion and adaptability-related factors.

To sum up, we could infer that there might be some correlation between family cohesion, family adaptability, and students' self-efficacy. The research would indicate a more specific relationship between family cohesion, family adaptability, and different college students' efficacy to enrich the existing studies. The differences in the impact of family cohesion and adaptability on college students of different grades could provide researchers with a new way to explore the reasons for such differences.

\section{PURPOSE OF THE STUDY}

Given these considerations, the purpose of the present study was to 1) To determine whether family 
cohesion may partially regulate the expected association between self-efficacy conditions among college students of all grades and 2) To explore whether there were significant differences in the correlation between family cohesion and self-efficacy among Chinese college students of four different grades.

Based on previous studies on education's social psychology [19], we predicted a positive correlation between family cohesion and Chinese college students of all four grades. College students with good family cohesion tended to have a high sense of self-efficacy, which depended on the purpose of the family's good advantages and development conditions. Their skills and abilities were cultivated in good family cohesion, such as academic resilience [11].

Although some studies had shown almost no differences between different student groups except friendship and learning environment satisfaction [20], based on first-year college students had exposure to unhealthy lifestyle behaviors that correlated with a high prevalence of anxiety and depression [21]. The lack of professional participation of parents had a direct negative impact on the career adjustment of Chinese graduates [22]. We would focus our study process on the freshman and junior students in Chinese as a population.

\section{METHOD}

\subsection{Participants}

We randomly selected 143 college students from all over China, including 33 freshmen, 31 sophomores, 41 juniors, and 38 seniors. Among the participants, 84 were female, and 59 were male. There were 33 history students, 87 science students, and 23 art students. Ninety-four students are from urban areas, and 49 are from rural areas.

\subsection{Materials and Procedure}

To assess self-efficacy, we used the revised General Self-Efficacy Scale (GSE). The General Self-efficacy scale was an evaluation tool for self-behavior, cognition, and attitude, by Schwarzer et al. [23]. It consisted of 10 items to understand the perspective, expectation, prediction of their behavior, and the effect of their behavior. Zhang and Schwarzer first used the Chinese version of GSE in 1995. Respondents were asked to rate the statements on the frequency they experienced these feelings using a 4-point Likert-type scale, ranging from 1 (degree) to 4 (disagree). Higher scores on the GSES indicated greater self-efficacy.

The scale for measuring Family Adaptability and Cohesion Evaluation Scale (FACES II) [24] was a selfreport scale, including two subscales, with 30 items.
Cohesion refers to the emotional connection between family members, and adaptability refers to the family system's ability to change according to family situations and problems in different stages of family development. The Chinese version (FACES II- CV) was revised for the third time by Shen et al. [25] because the environment of the Chinese family was very different from that of the Western. Responses to each item were graded on a five-point scale, and participants' responses represented the extent to which the conditions described in the item were present in their families, ranging from 1 (rarely) to 5 (almost always). For Family Adaptability and Cohesion Evaluation Scale, students needed to consider two things: the actual situation of their families and the ideal situation.

The questionnaire was sent to the mobile phones of the participating students via Wenjuanxing.

\section{RESULTS}

A total of 143 valid questionnaires (33 freshmen, 31 sophomores, 41 juniors, and 38 seniors) were included in the present analysis. Through data analysis, we found that the average score of family cohesion of all participants was 66.7 , which was in the "cohesion" state. We also found that there was an upward trend in family cohesion from freshmen to seniors. For family adaptability, the average score across all participants was the "regular" state at 45.35. Of the four grades, the average family adaptability of sophomores was the lowest and in the "rigid" state, while the rest were in the "regular" state. Finally, for the self-assessment data of self-efficacy, we found that the average score of participants in the four grades was 27.64. Among them, freshman scores are the highest and gradually decrease with the increase of grades.

Then we observed the multiply regression model we focused on. After putting the data into SPSS, it built us the multiply regression model. As it showed in the table, the R-square of the regression model was 0.186 . This multiple regression accounted for more than $18 \%$ of the variation in the count of Self-efficacy. According to the $\mathrm{P}$-value, it could be judged that family cohesion, family adaptability, and grade had a certain significant correlation to self-efficacy. Although it was not relatively large, it could mainly describe the real relationship because $\mathrm{R}$ square was just the ratio of the sum of the regression squares to the total sum of squares. With the data analysis from SPSS, we could write the equitation for the model: Self-efficacy $=$ $17.465+0.072 *$ Family Cohesion $+0.174 *$ Family Adaptability $-0.975 *$ Grade. The relationship between the family cohesion and family adaptability as independent variables with the dependent variable was all positive correlation and the intercept. Only grade had a negative relationship with the response variable. In other words, self-efficacy increased with the increase of 
family cohesion and family adaptability but decreased with grades. Specific results are shown in Table 1.

Table 1. Regression analysis between variables

\begin{tabular}{lllll}
\hline & $\begin{array}{l}\text { Standard } \\
\text { error }\end{array}$ & Beta & t & Significance \\
& & & & \\
\hline Constant & 2.824 & & 6.185 & .000 \\
Family & .042 & .144 & 1.713 & .089 \\
cohesion & & & & \\
Family & .046 & .316 & 3.777 & .000 \\
Adaptability & & & & \\
Grade & .349 & -.215 & - & .006 \\
& & & 2.797 &
\end{tabular}

Pearson product difference correlation method was used to analyze self-efficacy, students' actual family cohesion, and actual family adaptability. The results showed that there were significant positive correlations among the three. The correlation coefficient $(r)$ is between 0.245 and 0.401 . The analysis showed that there was a strong correlation between self-efficacy and family cohesion $(\mathrm{P}=0.0245<0.05)$ and a strong correlation between self-efficacy and family adaptability $(\mathrm{P}=0.0358<0.05)$. Specific results are shown in Table 2 .

Table 2. Pearson product difference correlation coefficient between variables $=143$ )

\begin{tabular}{lccccc}
\hline & $M$ & $S D$ & 1 & 2 & 3 \\
\hline $\begin{array}{l}\text { Self- } \\
\text { efficacy }\end{array}$ & 27.640 & 5.048 & 1 & & \\
$\begin{array}{l}\text { Family } \\
\text { cohesion }\end{array}$ & 66.700 & 10.065 & $.245^{\star *}$ & 1 & \\
$\begin{array}{l}\text { (actual) } \\
\begin{array}{l}\text { Family } \\
\text { adaptability } \\
\text { (practical) }\end{array}\end{array}$ & 45.350 & 9.158 & $.358^{* *}$ & $.401^{* *}$ & 1 \\
& & & & & \\
\hline
\end{tabular}

Note: * $\mathrm{P}<0.01$, ** $\mathrm{P}<0.05$, *** $\mathrm{P}<0.001$, double tail, same below.

\section{DISCUSSION}

Based on the result above, we drew the following conclusions. First of all, from the students' grade, the grade of students and self-efficacy was negatively correlated. That was, the higher the grade, the lower the student's sense of self-efficacy. As students got higher grades, they were more inclined to think that they would fail when doing something. The previous results of scholars showed that college students in higher grades were more likely to receive negative information from more sources, which led to their lower self-efficacy [26]. The grade of students was positively correlated with family cohesion. That was, the higher the grade, the stronger the emotional connection between them and the family. As the students get higher grades, they may understand their parents, and the emotional connection becomes more robust.

Meanwhile, the longer they spent away from their parents at school, the more they valued family connections. Researches have investigated that family cohesion was a significant predictor of the homesickness experience of college students. Family dependence was an essential predictor of the homesickness experience [27]. The result also supported our results and explains why family cohesion increased with age for college students.

Second, family intimacy and family adaptability were positively correlated with self-efficacy. Students were more likely to believe they could do something if they had stronger emotional connections with their family communication. Family relationship was like a bond that connected the college students. When students are in a negative psychological state, family cohesion positively could give students psychological support. The result was consistent with Coleman \& Karraker's [28] finding that self-efficacy was a strong predictor of parental function and family performance. Once parents had internalized a sense of competence in their roles, the satisfaction and pleasure of parenting could be achieved even in marginal ecological conditions. Suggesting that improving students' sense of self-efficacy was strongly correlated with positive family cohesion and family environment.

\section{CONCLUSION}

Family cohesion and adaptability were both critical influences on the family environment, and previous research had shown that the family environment had a significant effect on self-efficacy. However, less research in this area has focused on family cohesion factors in the family environment. Thus, the present study focused on the influence of family cohesion and adaptability on Chinese college students' self-efficacy from the factors influencing self-efficacy. Widening the scope of research on self-efficacy increased theoretical research on Chinese college students in the theoretical aspect. The practical aspect based on the study of family multifaceted overall could serve as solid theoretical support for shaping a good family atmosphere and 
helped promote family relationships and members' healthy development.

\section{REFERENCES}

[1] Bandura, A. (1997). Self-Efficacy: The Exercise of Control. New York, NY: W.H. Freeman and Co.

[2] Bandura, A. (1993). Perceived self-efficacy in cognitive development and functioning. Educational psychologist, 28(2), 117-148.

[3] Coleman, J. S., Campbell, E. Q., Hobson, C. J., Mcpartland, J., \& York, R. L. (1966). Equality of educational opportunity study. American Sociological Review, 32(3).

[4] Olson, D. H., Russell, C. S., \& Sprenkle, D. H. (1983). Circumplex model of marital and family systems: V1. Theoretical update. Family Process, 22(1), 69-83.

[5] Barbarin, O. A. (1984). Measuring basic family processes: Validity and reliability of Family Process Scale. Unpublished manuscript.

[6] Amani, N., Vahabi, A., Sayyad, S., Latifi, S., Kashefi, H., \& Narmashiri, A. (2018). Evaluation of the relationship between family cohesion and academic burnout in the students of Kurdistan University of Medical Sciences in 2016. Scientific Journal of Nursing, Midwifery and Paramedical Faculty, 4(2), 17-26.

[7] Ahmad, A., \& Safaria, T. (2013). Effects of selfefficacy on students' academic performance. Journal of Educational, Health, and Community Psychology, 2(1), 22-18.

[8] Nabunya, P., Bahar, O. S., Chen, B., Dvalishvili, D., Damulira, C., \& Ssewamala, F. M. (2020). The role of family factors in antiretroviral therapy (ART) adherence self-efficacy among HIV-infected adolescents in southern Uganda. BMC public health, 20(1), 1-9.

[9] Yi, X., Shui X., \& Huang Q. (2014). Influence of Family Environment on the Self-efficacy of College Students. Theory research, 8, 279-279.

[10] Sbicigo, J. B., \& Dell'Aglio, D. D. (2012). Family environment and psychological adaptation in adolescents. Psicologia, Reflexão e Crítica, 25(3), 615-622.

[11] Haibin Li, Andrew J. Martin \& Wei-Jun Jean Yeung (2017). Academic risk and resilience for children and young people in Asia, Educational Psychology, 37:8, 921-929.

[12] Liu, L., Liu, C., \& Zhao, X. (2017). Mapping the paths from styles of anger experience and expression to obsessive-compulsive symptoms: the moderating roles of family cohesion and adaptability. Frontiers in Psychology, 8.

[13] Xiang, G., Li, Q., Du, X., Liu, X. \& Chen, H. (2021). Links between family cohesion and subjective well-being in adolescents and early adults: the mediating role of self-concept clarity and hope. Current Psychology.

[14] Izenstark, D. \& Ebata, A. T. (2017). The Effects of the natural environment on attention and family cohesion: An experimental study. Children, Youth and Environment, 27(2).

[15] Ross, S. E., Niebling, B. C., \& Heckert, T. M. (1999). Sources of stress among college students. College student journal, 33, 312-317.

[16] Chemers, M., Hu, L., \& Garcia, B. (2001). Academic self-efficacy and first-year college student performance and adjustment. Journal of Educational Psychology, 93(1), 55-64.

[17] Zajacova, A., Lynch, S. M., \& Espenshade, T. J. (2005). Self-efficacy, stress, and academic success in college. Research in Higher Education, 46(6), 677-706.

[18] Guassi Moreira, J. F., \& Telzer, E. H. (2015). Changes in family cohesion and links to depression during the college transition. Journal of Adolescence (London, England.), 43, 72-82.

[19] Weiser, D. A., \& Riggio, H. R. (2010). Family background and academic achievement: does selfefficacy mediate outcomes? Social Psychology of Education, 13(3), 367-383.

[20] Qunying Gong, Ying Xie \& Tianmei Zhou (2011), On the Subjective Well - being of Different Student Groups in Colleges and Universities, Journal of Neijiang Normal university.

[21] Chenchen Gao, Yumei Sun, Feifei Zhang, Fang Zhou, Chaoqun Dong, Ziwei Ke, Qingyan Wang, Yeqin Yang, Hongyu Sun (2021), Prevalence and correlates of lifestyle behavior, anxiety and depression in Chinese college freshman: A crosssectional survey, International Journal of Nursing Sciences.

[22] Guan, Y., Wang, F., Liu, H., Ji, Y., Jia X., Fang, Z., Li, Y., Hua H., \& Li, C. (2015), Career-specific parental behaviors, career exploration and career adaptability: A three-wave investigation among Chinese undergraduates, Journal of Vocational Behavior, 86(Feb.), 95-103.

[23] Schwarzer, R. and Jerusalem, M. (1995) Generalized Self-Efficacy Scale. In: Weinman, J., 
Wright, S. and Johnston, M., Eds., Measures in Health Psychology: A User's Portfolio. Causal and Control Beliefs, Nfer-Nelson, Windsor, 35-37.

[24] Olson, D. H., Portner, J. \& Bell, R.Q. (1982). FACES II: Family Adaptability and Cohesion Evaluation Scales. Minnesota: Family Social Science, University of Minnesota, 22(1), 69-83.

[25] Shen, Q., Zhao, J., F, L., Zou, D. \& Zhou, Y. (1991). Preliminary Evaluation of Chinese version of FACES II and FES: Comparison of Normal Families and Families of Schizophrenic Patients.

[26] Mozahem, N. A., Boulad, F. M., \& Ghanem, C. M.Secondary school students and self-efficacy in mathematics: Gender and age differences. International Journal of School \& Educational Psychology, ahead-of-print(ahead-of-print), 1-11.

[27] Kazantzis, N., \& Flett, R. (1998). family cohesion and age as determinants of homesickness in university students. Social Behavior and Personality, 26(2).

[28] Coleman, P. K., \& Karraker, K. H. (1998). Selfefficacy and parenting quality: Findings and future applications. Developmental Review, 18(1), 47-85. 